\title{
COLONIZACION DE UNA CEPA DE PSOROPHORA (GRABHAMIA) CONFINNIS ARRIBALZAGA, 1891 EN COLOMBIA
}

\author{
VICTOR ALBERTO OLANO.* ALBERTO MORALES**
}

\begin{abstract}
Una colonia de Psorophora confinnis Arribalzaga, 1891, vector eficiente de Encefalitis Equina Venezolana tipo epidemoepizoótico se estableció en el laboratorio a partir de formas inmaduras y adultos, colectados en una región del municipio de Ambalema en el Departamento del Tolima; esta colonia se ha mantenido por 46 generaciones en un insectario localizado en el Municipio de Armero (Tolima).
\end{abstract}

Armero está a $352 \mathrm{mts}$. de altura sobre el nivel del mar.

Las hembras se alimentan con ratón blanco Suizo.

\section{INTR ODUCCION:}

Psorophora confinnis es un eficiente vector del virus de la Encefalitis Equina Venezolana tipo epidemo-epizoótico (1). Los brotes epidémicos y o epizoób́ticos debidos a este virus son de corta duración y una vez que terminan éstos, el virus desaparece sin que se sepa en dónde se mantienen estas cepas en los perlodos interepidémicos. Para aclarar este interrogante se ha planteado la siguiente hipótesis: El virus enzob́tico (no patógeno para el equino pero si para el humano) hace incursiones fuera de su habitat, y por mecanis. mos que se desconocen se transforma en tipo epidemo-epizobtico por paso a través de vectores y hospederos adecuados. Para probar la validéz de esta hipótesis se hace necesaria la colonización de una de las especies vectoras de la Encefalitis Equina Venezolana tipo epidemo-epizoótico que permita realizar los estudios de transmisión de este virus.

La especie $\mathbf{P}$ sorophora confinnis presenta una amplia distribución en el Continente

Biólogo, Instituto Nacional de Salud. Sección de Entomología. Apartado 8008 . Bogotá, Colombia.

** M. Sc. Instituto Nacional de Salud, Sección de Entomología, Apartado 80080. Bogotá, Colombia.
Americano encontrándose desde Estados Unidos hasta la Argentina (2). En Colombia se tienen registros en Pachaquiaro (Meta) Villavicencio (Meta), Neiva (Huila), Monteria (Córdoba), Girardot (Cundinamarca), Lebrija (Santander) (3) Saldaña y Purificación (Tolima) (4), Ambalema y Armero (Tolima), Riohacha, Maicao, Dibulla (Guajira), Campo Alegre (Huila), Cúcuta (Norte de Santander) y Puerto Boyacá (Boyacá) (5).

En la naturaleza las formas inmaduras de esta especie se encuentran en depresiones del suelo que acumulan agua de lluvia pero principalmente en zonas arroceras donde al adulto se le conoce con el nombre vernáculo de "mosquito negro de los arrozales". Aún cuando se conocen muchos datos sobre la biologia y ecologia de Psorophora confinnis (6) no parece haber sido establecida, hasta donde fue posible investigar, una colonia continua de este mosquito, considerándose que ésta es la primera vez que se coloniza esta especie.

\section{MATERIALES Y METODOS}

Para su colonización se colectaron adultos y formas inmaduras (larvas y pupas) en un cultivo de arroz de la hacienda "Alfaya" en la vereda Cuatro Esquinas, Municipio Ambalema 
(Tolima). Los adultos se capturaron agitando una red caza-mosquitos sobre el cultivo, lugar donde usualmente se encuentran reposando. Algunos ejemplares fueron capturados con cebo humano. Los mosquitos colectados se sacaron de la red caza-mosquitos por medio de un aspirador de boca, fueron guardados en frascos Bordas (frascos de vidrio recubiertos internamente con yeso para prevenir el agua de condensación), y de esta manera fueron transportados al insectario. Las formas inmaduras (larvas y pupas) se colectaron de los criaderos utilizando cucharones esmaltados y goteros de vidrio y fueron empacadas en bolsas plásticas para su transporte al laboratorio. Las primeras capturas se realizaron durante el dia, el 8 y 9 de febrero de 1978. Fue necesario realizar dos viajes por semana durante un mes al lugar de colección con el objeto de incrementar la colonia.

El material colectado en el campo se llevó al insectario del Instituto Nacional de Salud en Armero (Tolima), el cual poseía las condiciones necesarias de luz, humedad y temperatura adecuadas para la adaptación de la especie. El sitio en donde está localizado el insectario está a 352 metros sobre el nivel del mar. Los adultos fueron colocados en jaulas de madera de $92 \mathrm{cms}$. de largo por $35 \mathrm{cms}$. de ancho por $52 \mathrm{cms}$. de alto.

Las hembras fueron alimentadas inicialmente con cebo humano. Posteriormente se les proporcionó sangre de ratón conato (Proechimys hendei), hamster (Mesocrisetus auratus) y ratón blanco Suizo los cuales se inmovilizaban en jaulas metálicas colgadas del techo de la jaula. Para obtener ovoposición se ensayaron cajas de Petri, las cuales llevaban en el fondo algodón humedecido cubierto con papel de filtro, tazas plásticas con agua y tazas plásticas con tierra humedecida a las cuales se les había sembrado arroz. Las larvas y pupas fueron colocadas en bandejas blancas esmaltadas de $57.5 \mathrm{cms}$. de largo por $38.5 \mathrm{cms}$. de ancho. Las larvas fueron alimentadas con galleta en trozos de la utilizada para alimentar ratones de laboratorio.

\section{RESULTADOS}

Adultos: En la actualidad los adultos se mantienen en jaulas ya descritas. Como fuente de sangre no humana para las hembras, los hamster y los ratones blanco Suizo, dieron muy buenos resultados. A las hembras se les suministra la alimentación dos horas durante la mañana y dos horas durante la tarde. Se les proporciona el alimento al poco tiempo de su emergencia. A adultos machos y hembras se les mantiene permanentemente bolas hechas de algodón y gasa impregnadas de una solución azucarada. Actualmente la colonia se mantiene a una temperatura y humedad relativa promedia de $27^{\circ} \mathrm{C}$ y $85 \mathrm{RH}$ respectivamente.

Huevos: La ovoposición se realiza sobre tierra humedecida en tazas plásticas de 11 $\mathrm{cms}$. de diámetro por $7.5 \mathrm{cms}$. de profundidad; estos recipientes les sirve también a los adultos como lugar de reposo. Para la postura de las hembras se deja en cada jaula un par de tazas con tierra durante una semana, transcurrida la cual las tazas se sacan de la jaula siendo remplazadas por otras. Cuando las tazas con los huevos se retiran de la jaula se dejan en incubación por 4 días con el objeto de que los últimos huevos depositados completen su período de incubación. Por último estas tazas se colocan en recipientes plásticos de $27.91 \mathrm{cms}$. de díametro y $10 \mathrm{cms}$. de profundidad los cuales contienen agua. Transcurrido un corto tiempo, de los huevos que se han puesto en contacto con el agua, comienzan a eclosionar las larvas.

Larvas: Cuando ha nacido la larva se adiciona el alimento el cual consiste de galleta de la utilizada para alimentar ratones tamizada en malla 20 (escala Tyler) esta comida antes de ser adicionada debe ser disuelta en un poco de agua; la comida se debe agregar en poca cantidad ya que su exceso hace que se desarrolle una película sobre la superficie del agua lo que ocasiona la mortalidad de la larva. Generalmente las larvas se dejan en estos recipientes hasta que completan su desarrollo y solamente cuando hay larva en exceso se transfieren a recipientes similares o bandejas esmaltadas blancas, ya que su hacinamiento impide un desarrollo normal de la misma e incluso puede ocasionar su muerte. A las larvas se les adiciona el alimento una vez por día.

Pupas: Todos los dias se revisan los recipientes plásticos y las bandejas. Cuando hay 
pupas éstas se retiran, se pasan a tazas iguales a las de postura y se colocan dentro de la jaula; las tazas son retiradas al emerger todos los adultos.

El tiempo promedio del ciclo para P sorophora confinnis en el laboratorio es el siguiente:

$\begin{array}{lll}\text { Huevo } & \text { Larva } & 4 \text { Días } \\ \text { Larva } & \text { Pupa } & 5 \text { Días } \\ \text { Pupa } & \text { Adulto } & 1 \text { Día }\end{array}$

En la actualidad se tiene en el insectario de Armero (Tolima) una colonia estable de P sorophora confinnis en la generación 46 y se continúa al intento de colonización en el insectario del laboratorio de Entomología en Bogotá.

\section{DISCUSION Y CONCLUSIONES:}

No se puede pensar en realizar experimentos de multiplicación del virus de la Encefalitis Equina Venezolana tipo epidemo-epizoótico en mosquitos, sin contar con una colonia estable de una de las especies vectoras eficientes, por lo cual se hacia indispensable tratar de colonizar alguna de ellas y es lo que se ha.logrado con P sorophora confinnis.

Es bien sabido que esta especie es una de las responsables de la transmisión en varios paises de América incluso Colombia. Varios intentos de colonización se habian hecho en diversos laboratorios con resultado negativo. Esta especie es fuertemente antropofilica por lo que inicialmente se hizo necesario alimentar las hembras con cebo humano; sin embargo y por razones obvias era necesario adaptarlas a picar en un animal de laboratorio. En un principio se tratb de alimentarlas con ratón conato (Proechimys hendei) y ratón blanco Suizo con muy malos resultados.

Posteriormente se utilizaron hamster y se encontró que eran un excelente cebo pero por dificultades en la producción de estos animales en la colonia, fue necesario volver a insistir con los ratones blanco suizos y después de unos tres meses se logró que los mosquitos se adaptaran a picar en este animal; actualmente las hembras se alimentan en estos ratones.
Se ensayaron tres métodos para la ovoposición de las hembras pero el único que dio resultado fue el de las tazas con tierra húmeda. Esto indica que las hembras de p. confinnis depositan sus huevos en condiciones naturales directamente sobre la superficie de la tierra húmeda. Para la alimentación de las larvas dio muy buenos resultados la galleta que se usa para alimentar ratones a condición que se les proporcione finamente pulverizada.

El ciclo evolutivo de P sorophora confinnis es muy corto, de huevo a adulto únicamente 10 días. Esto explica la enorme densidad en que se encuentra este mosquito en algunas áreas.

La colonia en el insectario de Armero se encuentra en la generación 46 , es decir, se ha obtenido una colonia estable de este mosquito.

A partir de huevos de la colonia de Armero se ha estado tratando de establecer una colonia en el laboratorio en Bogotá.

\section{R E S U M E N}

Una colonia de Psorophora confinnis Arribalzaga, 1891, vector eficiente de Encefalitis Equina Venezolana tipo epidemoepizoótico se estableció en el laboratorio a partir de formas inmaduras y adultos, colectados en una región del Municipio de Ambalema en el Departamento del Tolima; esta colonia se ha mantenido por 46 generaciones en un insectario localizado en el Municipio de Armero (Tolima). Armero está a 352 metros de altura sobre el nivel del mar.

Las hembras se alimentan con ratón blanco Suizo.

\section{S U M M A R Y}

A colony of Psorophora confinnis Arribalzaga, 1891, was established and have been successfully maintained for 46 generations in an insectary which it is situated in a small town name Armero in the Tolima department. Armero is 352 meters high on the sea lavel. 
Psorophora confinnis in an efficient vector of the Venezuelan Equine Encephalitis Virus, epidemic and epizootic type.

Aquatic stages and adults of $\mathbf{P}$ sorophora confinnis were obtained for colonization from the breeding area in the Ambalema country, fieds, Tolima, Department.

As a source of blood meals for females it was used white swiss mice.

\section{R E F E R E N C I A S}

1. Sudia, W.D., 1972. Arthropod vectores of epidemic Venezuelan Equine Encephalitis. PAHO, Washington D.C.: pp.157-169.

2. Forattini, O.P., 1965. Entomología Médica. Editora de Universidade de Sao Paulo. Sao Paulo Brasil. Vol. 11 : pp. 422-428.

3. Heinemann, S. J., and Belkin, J. N., 1978. Collection records of the project "Mosqui- toes of Middle America" Mosq. Syst. 10 (4): pp. 493-539.

4. Carrillo, P., y Ramírez, J., 1977. "Búsqueda de posibles reservorios y vectores de la Encefalitis Equina Venezolana en una región del Municipio de Purificación y Saldaña (Tolima). Tesis de grado para optar el título de Biólogo. Universidad Nacional de Colombia. Facultad de Ciencias. Departamento de Biología. Bogotá. Mimeógrafo.

5. Morales, A., Vidales, H., Groot, H., Comunicación personal.

6. Gerber, E. J., 1970. Manual for rearing and experimental techniques. Bull. No. 5. Amer. Cont. Ass. Inc. Baltimore : pp. 50-51.

\section{AGRADE CIMIENTOS}

Los autores expresan su agradecimiento al señor Alberto Pinzón por su valiosa cooperación en el mantenimiento de la colonia en el insectario de Armero (Tolima). 